Pak. j. sci. ind. res. Ser. A: phys. sci. 2016 59(3) 151-156

\title{
Removal of COD in Purified Terephthalic Acid (PTA) Effluent with Coagulation, Aqueous Oxidation and High Porosity Membrane
}

\author{
Niaz Ahmed Memon*a, Nisar Ahmed ${ }^{b}$, Sarwat Ismaila, Nusrat Jalbania, \\ Uzma Asghara, Tahira Ayaz ${ }^{\mathrm{b}}$ and Razia Begum ${ }^{\mathrm{a}}$ \\ ${ }^{a}$ PCSIR Laboratories Complex, Shahrah-e-Dr. Salimuzzaman Siddiqui, Karachi-75280, Pakistan \\ ${ }^{b}$ Leather Research Centre, PCSIR, D-102, S.I.T.E., South Avenue, Karachi-75700, Pakistan \\ (received June 18, 2015; revised January 25, 2016; accepted March 16, 2016)
}

\begin{abstract}
Present study was focused on purified terephthalic acid (PTA) industry wastewater treatment located at Port Qasim, Karachi. PTA wastewater containing high COD (100000 to $150000 \mathrm{mg} / \mathrm{L})$ was treated with coagulate ferrous ion and then was oxidized independently with aqueous hydrogen peroxide using different doses at $45{ }^{\circ} \mathrm{C}$ for $1 \mathrm{~h}$. The resulting wastewater was passed through $\mathrm{RO}$ plant equipped with high porosity bio-ceramic membrane. It was observed that coagulation and oxidation processes have potential to reduce $87.9 \%$ COD but complete reduction up to $99.8 \%$ was achieved after passing the effluents from high RO plant equipped with high porosity ceramic membrane.
\end{abstract}

Keywords: COD reduction, coagulation, active oxidation, ceramic membrane, purified terephthalic acid

\section{Introduction}

Purified terephthalic acid (PTA) is a refractory organic material and an imperative industrial chemical used as precursor for manufacturing good quality multipurpose plastics like PBT (poly butyl terephthalate), PET (polyethylene terephthalate), and bio-plastic i.e., PTT (polytrimethylene terephthalate). It is also utilized for the production of chemical fibres, pesticides, dyes etc. Because of its wide-ranging applications, significant manufacturing and chemical distinctiveness, terephthalic acid and its related organic compounds have become omnipresent as environmental contaminants, and they have been found in soil, aquatic systems, and associated organisms (Zhang et al., 2013).

In 1993, PTA production was estimated to be 425 to 525 million tonnes world over. In 2002, its annual growth rate increased to $7.5 \%$ and accounted for about 26.12 million tonnes, with China growth rate attributed for about 2.6 million tonnes. PTA demand further increased to 28.8 million tonnes in the year 2005, in which China contributed 12.14 million tonnes that is $42 \%$ of the total world demand (CR, 2007). During production of every ton of PTA, about 3-4 $\mathrm{m}^{3}$ of wastewater with $4-10 \mathrm{~kg} \mathrm{COD} / \mathrm{m}^{3}$ is produced (Shafaei et al., 2010; Karthik et al., 2008; Franck and Stadelhofer, 1988). Major portion of PTA wastewater comprises of benzoic acid (BA), phthalic acid (PA), $p$-toluic acid

\footnotetext{
*Author for correspondence; E-mail:niazmemon2000@yahoo.com
}

(p-Tol), 4-carboxybenzaldehyde (4-CBA), and terephthalic acid (TA) with minor concentrations of the $p$-xylene, methyl acetate and 4-formylbenzoic acid (Kleerebezem et al., 1999). The contribution of these chemicals towards COD in the wastewater, at times become more than $85 \%$.

US Environmental Protection Agency has recently added this class of chemicals to the list of priority pollutants (USEPA, 2007) because phthalate (its ester degradation intermediates) poses serious threat to human health causing acute, sub-acute, chronic and molecular toxicity. It is also reported that the exposure of pure chemical PTA causes impair renal damage, liver and testicular function, bladder cancer and inhibit microbial growth (Zhang et al., 2013; Chen et al., 2001; Qu et al., 2000). Therefore, treatment of PTA contamination is very essential not only to preserve and protect natural ecosystems but also to hinder its detrimental effect on human health (Pernille et al., 2007; Scholz, 2003; Qi et al., 2002).

Various methods are being used for the treatment of industrial wastewater to remove PTA world over like, supercritical water oxidation, ozone assisted photochemical oxidation $\left(\mathrm{UV} / \mathrm{O}_{3} / \mathrm{H}_{2} \mathrm{O}_{2}\right)$, advanced oxidation processes (AOP), UV-assisted ozonation $\left(\mathrm{UV} / \mathrm{O}_{3}\right)$, ozone-assisted photo-fenton oxidation $\left(\mathrm{UV} / \mathrm{O}_{3} / \mathrm{H}_{2} \mathrm{O}_{2} / \mathrm{FeSO}_{4}\right)$, photofenton oxidation $\left(\mathrm{UV} / \mathrm{H}_{2} \mathrm{O}_{2} / \mathrm{FeSO}_{4}\right)$, and radiation treatment using gammaray, treated with powdered and 
granular activated carbon and biological treatment (Satish, 2013; Anbia et al., 2012; Saleem et al., 2011; Aygun and Yilmaz, 2010; Zhu et al., 2010; Barbusiñski, 2005). Although these procedures have been developed to treat industrial wastewater but there are some limitations which restrict to use them like high cost, generation of sludge and toxic intermediates that consequent to secondary pollution.

The alternate approach is to lowering down the COD (chemical oxygen demand) which measures the oxygen status of the component in the wastewater. The COD actually indicates the pollution level and sewage contents and also provides a gauge which relates to the impending environmental threats of a wastewater. High influx of chemicals in effluents commences chemical reaction that consume high quantity of oxygen (i.e., high COD) resulting lowering of oxygen amount required for biological life (WDNR, 2007). Therefore, it is very important to maintain COD for protecting and conserving aquatic environment. There are several methods available for COD removal from wastewater i.e., electrochemical Fenton process, flocculation and advanced oxidation processes, activated carbon and low cost adsorbent (Eslami et al., 2013; Lakdawala and Lakdawala, 2013; Hussain et al., 2013; Rakholiya and Puranik, 2012; Aluyor and Badmus, 2008; Zayas et al., 2007). The aim of this study was to reduce COD level by coagulation, oxidation and reverse osmosis with high porosity membrane (bio-ceramic) (Zheng, 2012). The results show that this method has remarkable potential to remove COD from PTA wastewater.

\section{Materials and Methods}

All analytical analysis and experiments were performed in duplicate.
Apparatus. A model $3510 \mathrm{pH}$ meter Genway with glass electrodes was used for the $\mathrm{pH}, \mathrm{DR}-4000, \mathrm{HACH}$ Spectrophotometer was used for COD determination COD Reactor, HACH was used for digestion. Hot plate/electric stirror (HS 10 2, Torry Pines Scientific, USA) was used for stirring.

Chemicals and reagents. All chemicals employed in this study were of analytical grade (Merck, Darmstadt, Germany). All solutions were prepared in distilled/deionized water made on each experimental day. Glassware used for all experiments, was soaked with $\mathrm{HNO}_{3}(\sim 10 \%)$ for $24 \mathrm{~h}$, and rinsed with distilled/de-ionized water prior to drying. Hydrogen per oxide used was of analytical grade as $30 \% \mathrm{w} / \mathrm{v}$. The ferrous sulphate hepta hydrate $\left(\mathrm{FeSO}_{4} \cdot 7 \mathrm{H}_{2} \mathrm{O}\right)$ was used as the coagulation process. Solutions of $\mathrm{NaOH}$ and $\mathrm{HCl}$ were used for $\mathrm{pH}$ adjustments.

Sample collection and pretreatment. Sampling and analysis of the raw wastewater coming from PTA industry was done by taking grab sample (WDNR, 2007). The wastewater samples were collected directly from main drain on a week basis for segregation purpose. After collection, first analysed the COD parameter to determine the quality of the incoming raw wastewater (Table 1). Segregation of effluent means separation as per effluent characteristics. It is a new concept for wastewater minimization and optimizes the operation cost (Tchobanoglous et al., 2003).

Analytical method. Standard Methods were used for determination of COD (APHA, 1998). The $\mathrm{pH}$ measurements were performed using a $\mathrm{pH}$ meter $(3510 \mathrm{pH}$ meter Genway).

The test was conducted on the standard potassium hydrogen phthalate (KHP) solution to evaluate the

Table 1. Physicochemical characteristics of PTA raw water

\begin{tabular}{lllll}
\hline \hline & & & NEQS limits $(\mathrm{mg} / \mathrm{L})$ \\
\cline { 3 - 5 } Parameters & PTA effluent & into inland water & $\begin{array}{l}\text { into sewage } \\
\text { treatment }\end{array}$ & into sea \\
\hline Temperature $\left({ }^{\circ} \mathrm{C}\right)$ & & $\leq 3$ & $\leq 3$ & $\leq 3$ \\
$\mathrm{pH}$ & 3.3 & $6-9$ & $6-9$ & $6-9$ \\
$\mathrm{COD}(\mathrm{mg} / \mathrm{L})$ & 108,000 & 150 & 400 & 400 \\
$\mathrm{BOD}(\mathrm{mg} / \mathrm{L})$ & 476 & 80 & 250 & 80 \\
$\mathrm{TSS}(\mathrm{mg} / \mathrm{L})$ & 875 & 200 & 400 & 200 \\
TDS $(\mathrm{mg} / \mathrm{L})$ & - & 3500 & 3500 & 3500 \\
Oil \& grease $(\mathrm{mg} / \mathrm{L})$ & No traces & 10 & 10 & 10 \\
Sulphide $(\mathrm{S})(\mathrm{mg} / \mathrm{L})$ & No traces & 1.0 & 1.0 & 1.0 \\
Ammonia $\left(\mathrm{NH}_{3}\right)(\mathrm{mg} / \mathrm{L})$ & 147 & 40 & 40 & 40 \\
\hline \hline
\end{tabular}


technique and quality of reagents. At selected time interval, $5 \mathrm{~mL}$ of reaction mixture was taken and then analyzed for COD. The samples containing $\mathrm{H}_{2} \mathrm{O}_{2}$, which interfere with the COD measurements, were eliminated by the addition of $\mathrm{MnO}_{2}$ powder. Before each analysis, samples were centrifuged to remove $\mathrm{MnO}_{2}$ (Talinli and Anderson, 1992).

Methodology. Wastewater treatment was done in three phases such as coagulation, flocculation and oxidation using high porosity permeable membrane as shown in Fig. 1-2.

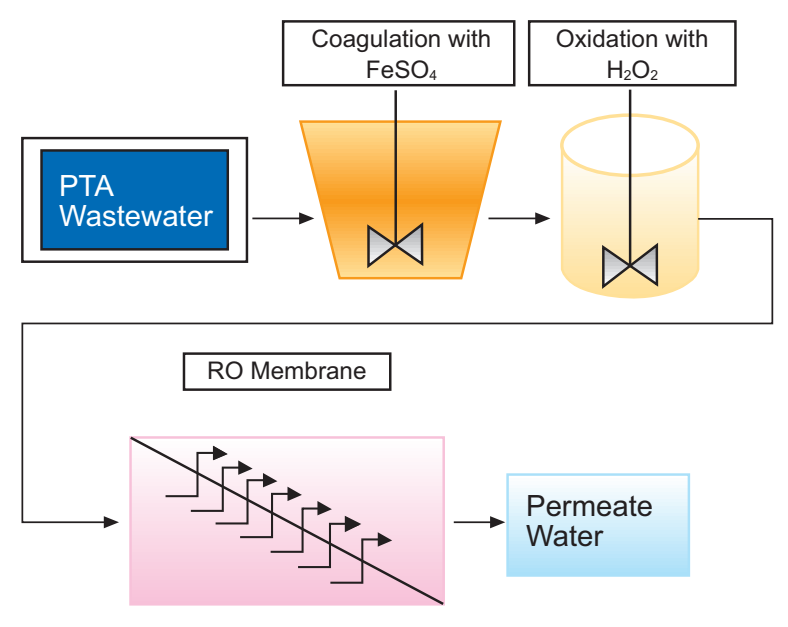

Fig. 1. PTA wastewater treatment flow diagram.
Raw wastewater samples were collected at random from industrial purified terephthalic acid (PTA) plant. This PTA plant manufactures a variety of multipurpose plastic products. The parameters like chemical oxygen demand (COD), biological oxygen demand for 5 days (BOD), total dissolved solids (TDS), total suspended solids (TSS), sulphides, ammonia, oil and grease, temperature and $\mathrm{pH}$ value of raw wastewater samples were performed before coagulation process.

Coagulation and flocculation. Coagulation and flocculation studies were performed in a standard jar-test apparatus (Jar Tester Model CZ150) comprises of six paddle rotors $(24.5 \mathrm{~mm} \times 63.5 \mathrm{~mm})$ and equipped with 6 beakers of $2 \mathrm{~L}$ volume. The commonly used metal coagulants fall into two general categories: (1) based on aluminium and (2) based on iron. This paper deals with the iron based coagulants that is ferrous sulphate. $\mathrm{FeSO}_{4}$ was applied on w/v basis i.e., 2, 4, 8, 10 and $12 \mathrm{~g} / 2000 \mathrm{~mL}$ of PTA waste water.

Before coagulation process, wastewater sample was thoroughly shaken to avoid possibility of settling solids. The experimental process consisted of the initial rapid mixing stage that took place for $10 \mathrm{~min}$ at $100 \mathrm{rpm}$, the following slow mixing stage for $45 \mathrm{~min}$ at $50 \mathrm{rpm}$ and the final settling step for $2 \mathrm{~h}$. After $2 \mathrm{~h}$ settling period, samples were withdrawn from supernatant for analyses. Process performance was monitored by analysis of COD values.

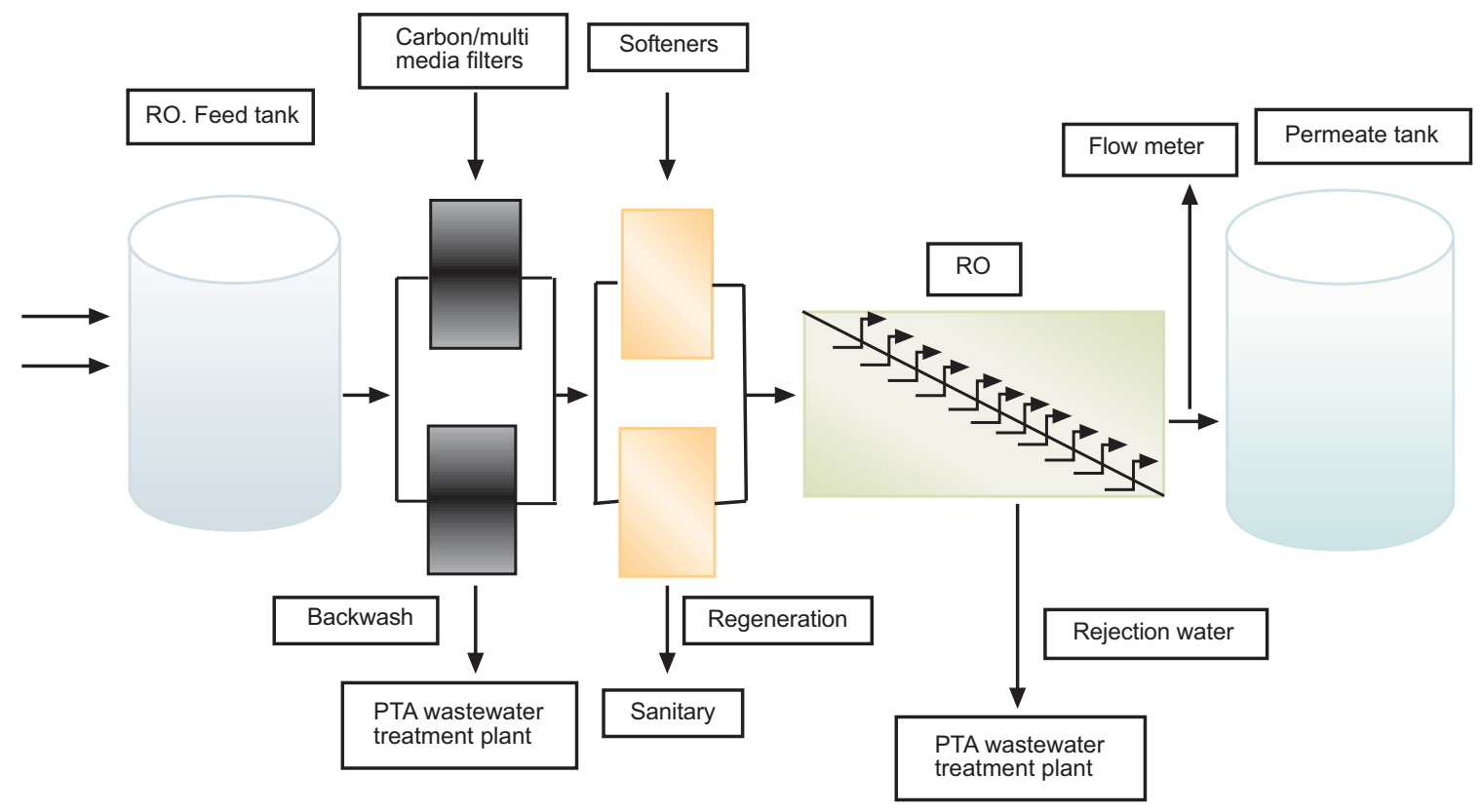

Fig. 2. RO flow diagram. 
Oxidation by hydrogen per oxide. The oxidation of the organic compounds in the wastewater samples was carried out to further reduce the COD. This oxidative step was carried out using $\mathrm{H}_{2} \mathrm{O}_{2}(0.5 \% \mathrm{v} / \mathrm{v})$ at $\mathrm{pH} 4.5$ for $60 \mathrm{~min}$. Coagulation supernatants were drawn in $1000 \mathrm{~mL}$ volume and labeled in six groups i.e., A, B, $\mathrm{C}, \mathrm{D}, \mathrm{E}$ and F. Hydrogen per oxide solution of known strength was prepared in de-ionized water in the range of concentration 4, 8, 12, 16, 18 and $20 \mathrm{~mL}$ and oxidized at $45^{\circ} \mathrm{C}$ temperature.

Nano filtration through bio- ceramic membrane. After oxidation supernatant wastewater sample was passed through high porosity of bio- ceramic membrane (CSM, Model No.RE1812-88). COD was measured after passing from the membrane.

\section{Results and Discussion}

Present study was carried out to determine different parameters in analyzed samples. The average values of COD and BOD were found higher than the prescribed National Environmental Quality Standard (NEQS) limits. The results are expressed in Table 1. The results show high values of COD, BOD and removal of some or all of the contaminants making it fit for reuse or discharge back to the environment. Diseases have often been caused by discharging untreated or inadequately treated wastewater. Such discharges are called water pollution. The pollution of water has a serious impact on all living creatures, and properly treating wastewater assures that overall acceptable water quality is maintained.

Coagulation and flocculation process. Coagulation flocculation is also a common chemical water treatment process to treat industrial and domestic wastewater in order to remove suspended particles from the water. The raw wastewater produced by the industrial PTA plant a COD of $100,000-150,000 \mathrm{mg} / \mathrm{L}$. During the course of coagulation-flocculation treatment selection of coagulant is the biggest problem to disperse the pollutants. In this process ferrous sulphate as a coagulant was assessed. Typically, results showed that this procedure is dependent on $\mathrm{pH}$ and concentration of ferrous sulphate, as a coagulant to remove COD and total suspended solids. When ferrous sulphate $(10 \mathrm{mg} / \mathrm{L})$ was added at $\mathrm{pH}=4.46,65 \%$ of $\mathrm{COD}$ was removed. Hence, this shows that ferrous sulphate was more effective for PTA wastewater treatment. The results obtained from chemical coagulation to the raw PTA wastewater and iron coagulants ferrous sulphate at $10 \mathrm{~g} / 2 \mathrm{~L}$ is listed in Table 2. The reduction of COD was observed in order of $7.7,24.3,37.5,50.8,65.0$ and $65.0 \%$.

Oxidation process. The results are summarized in Table 3. However, the presence of coagulant caused a reduction in COD up to $65 \%$. Subsequent oxidation treatment caused a further decrease in COD. After irradiation of $60 \mathrm{~min}, \mathrm{COD}$ had been reduced to 12987 $\mathrm{mg} / \mathrm{L}$ with the maximum volume of $\mathrm{H}_{2} \mathrm{O}_{2}$ at $18 \mathrm{~mL} / \mathrm{L}$ which correspond to COD reduction in order of 77 , $82.4,87.7,87.8,87.9$ and $87.9 \%$, respectively. In advanced oxidation processes, $\mathrm{pH}$ has a noteworthy effect on the removal efficiency of organic compounds. This study observed the effect of $\mathrm{pH}$ changes on the removal efficiency (Eslami et al., 2013; Lakdawala et al., 2013; Hussain et al., 2013), so the oxidative degradation processes were carried out at the initial $\mathrm{pH}$ of the PTA wastewater (5.1-6.8) and repeated at various other $\mathrm{pH}$ values (both acidic and alkaline).

Table 2. Effect of coagulation on COD

\begin{tabular}{llll}
\hline \hline $\begin{array}{l}\text { Adsorption dose } \\
(\mathrm{g})\end{array}$ & $\mathrm{pH}$ & $\begin{array}{l}\text { Concentration } \\
(\mathrm{mg} / \mathrm{L})\end{array}$ & $\begin{array}{l}\text { Removal } \\
(\%)\end{array}$ \\
\hline Fresh & 3.3 & 108,000 & - \\
2 & 3.7 & 99,700 & 7.7 \\
4 & 4.1 & 81,300 & 24.3 \\
6 & 4.5 & 67,500 & 37.5 \\
8 & 4.7 & 53,100 & 50.8 \\
10 & 4.9 & 37,800 & 65.0 \\
12 & 5.1 & 37,800 & 65.0 \\
\hline \hline
\end{tabular}

Coagulation with ferrous sulphate at different adsorbent doses in weight by volume (volume $=2 \mathrm{~L}$; contact time $=1 \mathrm{~h}$; temperature $=25^{\circ} \mathrm{C}$; mixing speed $=45-50 \mathrm{rpm}$ ).

Table 3. Effect of oxidation on COD

\begin{tabular}{llll}
\hline \hline $\begin{array}{l}\text { Oxidant dose } \\
(\mathrm{mL})\end{array}$ & $\mathrm{pH}$ & $\begin{array}{l}\text { Concentration } \\
(\mathrm{mg} / \mathrm{L})\end{array}$ & $\begin{array}{l}\text { Removal } \\
(\%)\end{array}$ \\
\hline After coagulation & 5.1 & 37,800 & 65.0 \\
4 & 5.4 & 24765 & 77.0 \\
8 & 5.9 & 18959 & 82.4 \\
12 & 6.3 & 13200 & 87.7 \\
16 & 6.5 & 13167 & 87.8 \\
18 & 6.7 & 12987 & 87.9 \\
20 & 6.8 & 12987 & 87.9 \\
\hline \hline
\end{tabular}

Oxidized with hydrogen per oxide at different doses (volume $=1 \mathrm{~L}$; contact time $=1 \mathrm{~h}$; temperature $=45^{\circ} \mathrm{C}$; mixing speed $=120-130 \mathrm{rpm}$ ). 
RO (Nano technology) process. In this study, coagulationflocculation was examined as a pretreatment procedure for the treatment of PTA wastewater. The result of different organic and inorganic coagulants on the treatment of wastewater collected from flow coagulation of an effluent treatment and contaminated supplementary membrane was studied. Furthermore, PTA wastewater was treated and passed through nano based RO system with high porosity permeable membrane (bio-ceramic) (Pradeep et al., 2009, as shown in RO flow diagram (Fig. 2). Rejection of RO water dropped in the first stage i.e., mixing tank.

After this study, results obtained were compared with NEQS limits. At optimum conditions, COD of the waste water was reduced by high COD rejection values shows superior class of the permeate stream which correspond to COD reduction on the NEQS limit (148 $\mathrm{mg} / \mathrm{L}$ ) removed 99.8\% shown in Table 4.

The graphically presented results (Fig. 3) reveal a comparison of COD removal in coagulation and flocculation $(65 \%)$, in oxidation $(87.9 \%)$ and in RO (99.8\%).

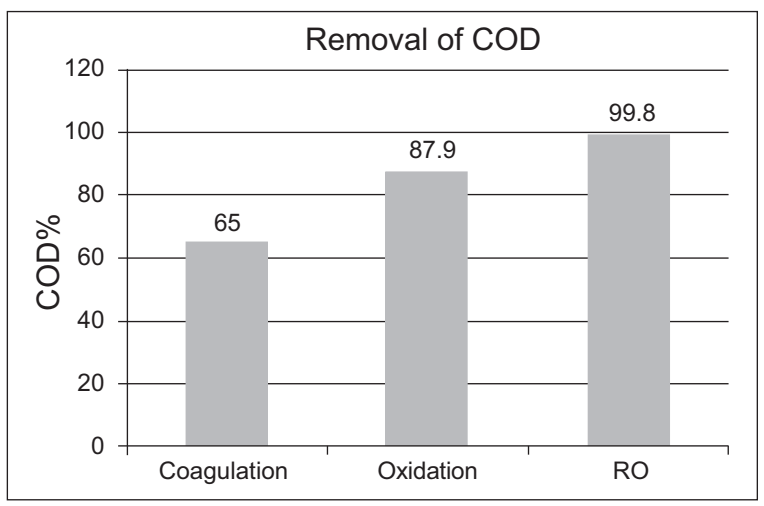

Fig. 3. Efficiency of COD reduction in PTA wastewater.

Table 4. Effect of application of advance RO on COD

\begin{tabular}{lll}
\hline \hline Process & $\begin{array}{l}\text { Concentration } \\
(\mathrm{mg} / \mathrm{L})\end{array}$ & $(\%)$ \\
\hline After oxidation & 12987 & 87.9 \\
Pass out through RO & 148 & 99.8 \\
(bio-ceramic & & \\
membrane) & & \\
\hline \hline
\end{tabular}

$\overline{\mathrm{RO}}$ pressure at $350 \mathrm{psi}$.

\section{Conclusion}

It is concluded that this method is very efficient, economical and robust and can be reproduced at large scale level at PTA wastewater for the lowering of COD. The results of coagulation, oxidation and nano technology (RO) process show about $99.8 \%$ in COD reduction, which open a new process to reduce the organic and inorganic (ester and intermediate etc) load of wastewater. This process can be successfully implemented to many chemical/pharmaceutical manufacturing factories which will help in reducing water pollution in terms of COD.

\section{References}

Aluyor, E.O., Badmus, O.A.M. 2008. COD removal from industrial wastewater using activated carbon prepared from animal horns. African Journal of Biotechnology, 7: 3887-3891.

Anbia, M., Salehi, S. 2012. Synthesis of polyelectrolytemodified ordered nanoporous carbon for removal of aromatic acids from purified terephthalic acid wastewater. Journal of Chemical Engineering Research and Design, 90: 975-983.

APHA, 1998. Standard Methods for the Examination of Water and Wastewater, $20^{\text {th }}$ edition, American Public Health Association, Washington DC., USA.

Aygun, A., Yilmaz, T. 2010. Improvement of coagulation flocculation process for treatment of detergent wastewaters using coagulant aids. International Journal of Chemical and Environmental Engineering, 1: 97-101.

Barbusiñski, K. 2005. Toxicity of industrial wastewater treated by Fenton's Reagent. Polish Journal of Environmental Studies, 14: 11-16.

Chen, B.J., Yuan, Y.X., Wang, H.P. 2001. Joint effects of acetaldehyde, $p$-phthalic acid and ethylene glycol on growth of silver carp and grass carp. Journal of Fishery Sciences of China, 8: 73-76.

CR, 2007. Chinese Pure Terephthalic Acid Market Report. http://studio5.financialcontent.com/ financialvisions?ChannelID $=3191$ \& GUID $=$ 3460172 \& Page $=$ Media Viewer2008

Eslami, A., Moradi, M., Ghanbari, F., Mehdipour, F. 2013. De-colorization and COD removal from real textile wastewater by chemical and electrochemical Fenton processes: a comparative study. Journal of Environmental Health Science \& Engineering, 11: 31 .

Franck, H.G., Stadelhofer, J.W. 1988. p-Xylene and its derivates: Terephthalic acid, In: Industrial Aromatic 
Chemistry: Raw Materials, Process Products, H.G. Franck (ed.), pp. 283-290, Springer-Verlag, Berlin Germany.

Hussain, S., Shaikh, S., Farooqui, M. 2013. COD reduction of waste water streams of active pharmaceutical ingredient- Atenolol manufacturing unit by advanced oxidation-Fenton process. Journal of Saudi Chemical Society, 17: 199-202.

Karthik, M., Dafale, N., Pathe, P., Nandy, T. 2008. Biodegradability enhancement of purified terephthalic acid wastewater by coagulation-flocculation process as pretreatment. Journal of Hazardous Materials, 154: 721-730.

Kleerebezem, R., Hulshoff Pol, L.W., Lettinga, G. 1999. Anaerobic biodegradability of phthalic acid isomers and related compounds. Journal of Biodegradation, 10: 63-73.

Lakdawala, M.M., Lakdawala, J.M. 2013. Comparative study of effect of PAC and GAC on removal of COD contributing component of sugar industry waste water. Research Journal of Recent Sciences, 2: 90-97.

Pradeep, T., Anshup. 2009. Noble metal nanoparticles for water purification: A critical review. In: Nanotechnology Application for Clean Water, Thin Solid Films, 517: 6441-6478.

Pernille, E., Kristian, K., Brandt, A., Rasmussen, L.H., Ovesen, R.G., Sørensen, D.J. 2007. Microbial degradation and impact of Bracken toxin ptaquiloside on microbial communities in soil. Chemosphere, 67: 202-209.

Qi, S.T., Wang, X.R., Xu, X.K. 2002. Study on the bladder calculi and bladder cancer induced by terephthalic acid in rats. Journal of Hygiene Research, 31: 10-12.

Qu, K.M., Yuan, Y.X., Chen, M.S. 2000. Acute toxicity and join effect of pollutants in fiber wastewater in Daphnia magna. Journal of Fishery Sciences of China, 7: 78-81.

Rakholiya, V.V., Puranik, S.A. 2012. COD reduction using modifying industrial effluent treatment flow sheet and low cost adsorbent as a part of cleaner production. Advances in Applied Science Research, 3: 1279-1291.

Satish, I.C. 2013. Electro coagulation: A novel waste water treatment method. International Journal of Modern Engineering Research (IJMER), 3: 93-100.

Saleem, M., Bukhari, A.A., Akram, M.N. 2011. Electro coagulation for the treatment of wastewater for reuse in irrigation and plantation. Journal of Basic and Applied Sciences, 7: 11-20.

Shafaei, A., Nikazar, M., Arami, M. 2010. Photocatalytic degradation of terephthalic acid using titania and zinc oxide photo catalysts: Comparative study. Desalination, 252: 8-16.

Scholz, N. 2003. Eco-toxicity and biodegradation of phthalate monoesters. Chemosphere, 53: 921-926.

Tchobanoglous, G., Burton, F. L., Stensetl, H.D. 2003. Wastewater Engineering: Treatment and Reuse, $4^{\text {th }}$ edition, Tata McGraw- Hill, New Delhi, India.

Talinli, I., Anderson, G.K. 1992. Interference of hydrogen peroxide on the standard COD test. Water Research, 26: 107.

US. Environmental Protection Agency, Federal Register (2007).

WDNR, 2007. Wastewater Sampling, Preservation and Analysis Methods, Wisconsin Department of Natural Resources, www.dnr.wi.gov.

Zeng, Z. 2012. Phosphorus Removal by Ceramic Tight Ultra-filtration (CTUF) Membranes for RO Pretreatment, Master Thesis, Delft University of Technology, The Netherlands.

Zhang, Y-M., Sun, Y-Q., Wang, Z-J., Zhang, J. 2013. Degradation of terephthalic acid by a newly isolated strain of Arthrobacter sp.0574. South African Journal of Science, 109. Art. \#0019, 4 pages. $\mathrm{http}: / / \mathrm{dx}$.doi.org/10.1590/.

Zhu, G.F., Wu, P., Wei, Q.S., Lin, J.Y., Gao, Y.L., Liu, H.N. 2010. Biohydrogen production from purified terephthalic acid (PTA) processing wastewater by anaerobic fermentation using mixed microbial communities. International Journal of Hydrogen Energy, 35: 8350-8356. 